\title{
Perbaikan Produktivitas melalui Green Productivity
}

\author{
Ignatius Geral Violi Hutagalung ${ }^{1}$, Vetty Kartikasari ${ }^{*}$ \\ ${ }^{12}$ Prodi Teknik Industri,Universitas Merdeka Malang \\ *Korespondensi Penulis, E-mail: kartikasari@unmer.ac.id
}

\begin{abstract}
Abstrak
PT ABC Malang merupakan salah satu industri penyamakan kulit yang memiliki potensi pencemaran limbah, sehingga diperlukan penanganan dan pengolahan limbah secara efektif dan efisien. Permasalahan perusahaan adalah tingginya volume sludge yang dikirim ke PPLI, sehingga memberikan beban finansial bagi perusahaan. Kondisi ini berpengaruh terhadap tingkat produktivitas perusahaan yang belum memenuhi harapan manajemen. Sehingga penelitian ini dilakukan dengan tujuan memberikan solusi bagi perusahaan untuk menyelesaikan permasalahan dengan mengkompromikan dua kepentingan yaitu kepentingan bisnis dan kelestarian lingkungan melalui pedekatan Green Productivity (GP). Dari hasil pengolahan dan analisa data diketahui bahwa target dan tujuan perusahaan dalam menyelesaikan permasalahan adalah mereduksi jumlah sludge yang dikirim ke PPLI dengan mengurangi kadar air dalam sludge hingga mencapai 50\% dry solid. Penerapan konsep green productivity $(G P)$ dilakukan dengan menghitung nilai EPI (Environment Performance Indicator) sebagai tolak ukur kinerja lingkungan dan menyusun alternatif solusi permasalahan sesuai target dan tujuan perusahaan. Berdasarkan perhitungan Indeks EPI sebesar 0.959 menunjukkan performa lingkungan perusahaan dalam kondisi baik. Sedangkan dari 2 alternatif yang diusulkan, solusi terpilih untuk perbaikan produktivitas di PT ABC Malang adalah alternatif 1 dengan penghematan biaya tahunan $R p 365.173 .120$ serta nilai total produktivitas sebesar $129 \%$.
\end{abstract}

Kata kunci: Produktivitas, Green Productivity, Indeks EPI (Environment Performance Indicator)

\section{Pendahuluan}

Industri penyamakan kulit merupakan salah satu industri yang berpotensi mencemari lingkungan, untuk menghasilkan kulit tersamak dilakukan suatu proses dengan menggunakan berbagai bahan kimia berbahaya bagi parameter lingkungan dan kesehatan manusia. Sehingga industri penyamakan kulit harus memiliki sistem pengolahan limbah yang baik agar tidak limbah yang dihasilkan sesuai dengan baku mutu yang ditetapkan BAPEDAL.

PT ABC merupakan perusahaan penyamakan kulit di kota Malang, dalam aktivitas produksinya perusahaan menghasilkan limbah cair dan padat. Limbah cair merupakan limbah yang paling paling banyak dihasilkan dalam proses penyamakan kulit selain menimbulkan bau menyengat juga mengandung bahan kimia berbahaya seperti sodium sulfide, chrom, kapur dan ammonia. Untuk mengolah limbah cair, PT ABC Malang memiliki Instalasi Pengolahan Air Limbah (IPAL) untuk proses penjernihan air limbah. Dari proses ini dihasilkan endapan berupa limbah padat (sludge) yaitu limbah katagori B3 (bahan berbahaya dan beracun). Dikarenakan tidak memiliki ijin pengolahan limbah B3 maka sludge yang dihasilkan ditampung sementara waktu sebelum diambil untuk diolah oleh PPLI (Perusahaan Pengolah Limbah Industri).

Berdasarkan data perusahaan tahun 2018 mencatat volume sludge yang dikirim ke PPLI sebesar 240 ton dengan biaya pengolahan limbah padat sebesar 1.080.000.000. Tingginya volume sludge yang dikirim ke PPLI memberikan beban finansial yang relatif besar, sehingga bila tidak dikelola secara efektif dan efisien maka berdampak terhadap tingkat produktivitas PT ABC Malang.

Untuk itu PT ABC Malang memerlukan solusi untuk mengkompromikan perbedaan antara kepentingan bisnis untuk mencapai keuntungan maksimal dengan mempertimbangkan dan menjaga kelestarian lingkungan. Sumber pencemaran air dari limbah adalah masalah besar baik bagi masyarakat, pemerintah dan para ahli yang 
bekerja di bidang lingkungan, salah satu alasannya adalah karena sumber polutan yang tersebar tidak mudah diidentifikasi dan ditandai.[1]

Produktivitas sering dipakai sebagai sebagai alat ukur untuk menunjukkan seberapa efektif dan efisien dari sebuah sistem. Produktivitas total merupakan rasio dari total output (seluruh keluaran yang dihasilkan dari proses produksi) dengan total input (seluruh resource yang dimanfaatkan dalam kegiatan produksi) [2], sehingga untuk menghitung indeks produktivitas dari PT ABC Malang dapat menggunakan formulasi berikut ini :

$$
\text { Total Productivity }=\frac{\text { Total Output }}{\text { Total } \text { Input }} \quad \text {... Pers (1) }
$$

Untuk mengkolaborasi antara tingkat produktivitas dengan kinerja lingkungan perusahaan dapat menggunakan pendekatan Green productivity $(G P)$ merupakan suatu strategi untuk meningkatkan produktivitas perusahaan dan performansi kinerja lingkungan secara bersamaan dalam pembangunan sosial ekonomi secara menyeluruh [3]. Penerapan konsep GP diharapkan dapat memberikan perbaikan yang signifikan terhadap produktivitas serta kinerja lingkungan.

Adapun kerangka metodologi GP terdiri dari :

1. Getting Started adalah proses pengumpulan data dan proses identifikasi ruang lingkup penelitian, membentuk tim GP dan Walk Through Survey.

2. Planning, merupakan tahap identifikasi masalah dan penyebabnya serta menentukan tujuan dan target.

3. Generation and Evaluation yaitu tahap perumusan dan penentuan alternatif dengan mempergunakan beberapa metode yaitu :

A. Life Cycle Cost merupakan salah satu metode pengambilan keputusan secara stategis dengan mempertimbangkan keseluruhan biaya yang berkaitan dengan kegiatan operasional perusahaan seperti biaya listrik, air, tenaga kerja, bahan baku, bahan penunjang kimia dan biaya pengolahan limbah.

B. Metode perhitungan tingkat pengembalian mempergunakan dengan deret seragam (annual worth)[4], sehingga akan berlaku hubungan :

$$
\mathrm{EUAR}-\mathrm{EUAC}=0
$$

EUAR (Equivalent Uniform Annual Revenue) merupakan suatu deret seragam yang menyatakan aliran kas masuk (pendapatan) per tahun dan EUAC (Equivalent Uniform Annual Cost) merupakan suatu deret seragam yang menyatakan aliran kas keluar (pengeluaran) per tahun

Dalam penerapan konsep green productivity tidak terlepas dari aktivitas pengukuran kinerja lingkungan untuk mengetahui hasil dari sebuah proses produksi Environmental Performance Indicator (EPI) merupakan tolak ukur performansi dari efisiensi dari aktivitas perusahaan terhadap lingkungan [5]. Perhitungan Indeks EPI dapat dirumuskan sebagai berikut :

$$
\text { Indeks } \mathrm{EPI}=\sum_{i-1}^{k} W i P i \ldots \text { Persamaan (3) }
$$

Dimana $k$ adalah Jumlah kriteria limbah yang diajukan, Wi merupakan bobot dari setiap kriteria sedangkan $P$ yaitu prosentase penyimpangan antara standar baku mutu peraturan pemerintah dengan hasil analisa kadar limbah perusahaan yang dihitung dengan persaman berikut :

$$
\mathrm{Pi}=\frac{\text { Standar BM-Hasil Analisa }}{\text { Standar BM }} \text { X } 100 \% \quad \ldots \ldots . . . \text { Pers (4) }
$$




\section{Metode Penelitian}

Penelitian ini mengadopsi konsep green productivity (GP) sebagai strategi peningkatan produktivitas dan kinerja lingkungan secara bersamaan. Teknik pengumpulan data primer dilakukan melalui obeservasi, wawancara, brainstorming serta survey lapangan sehingga didapatkan berbagai informasi yang relevan terkait pemasalahan yang terjadi di perusahaan. Data sekunder langsung yang dipakai dalam penelitian berupa jurnal dokumen catatan, bukti dan laporan keuangan perusahaan, sedangkan data sekunder tidak langsung diperoleh melalui website dan jurnal .

\section{Hasil dan Pembahasan}

3.1 Menghitung Indeks Produktivitas PT ABC Malang

Berdasarkan data perusahaan, hasil perhitungan indeks produktivitas berdasarkan formulasi produktivitas total menurut Sumanth dalam [1] diperoleh indeks produktivitas PT ABC Malang sebagai berikut :

Tabel. 3.1 Tingkat Produktivitas PT ABC Malang Tahun 2018

\begin{tabular}{|c|cr|rr|c|}
\hline Periode & \multicolumn{2}{|c|}{$\begin{array}{c}\text { Total Output } \\
\text { (Rp Juta) }\end{array}$} & \multicolumn{2}{|c|}{$\begin{array}{c}\text { Total Input } \\
\text { (Rp Juta) }\end{array}$} & Produktivitas (\%) \\
\hline Januari & $\mathrm{Rp}$ & 1.026 .118 .136 & $\mathrm{Rp}$ & 926.783 .189 & $110,72 \%$ \\
\hline Februari & $\mathrm{Rp}$ & 1.488 .202 .643 & $\mathrm{Rp}$ & 1.115 .985 .851 & $133,35 \%$ \\
\hline Maret & $\mathrm{Rp}$ & 944.982 .417 & $\mathrm{Rp}$ & 837.872 .957 & $112,78 \%$ \\
\hline April & $\mathrm{Rp}$ & 1.575 .368 .387 & $\mathrm{Rp}$ & 1.183 .535 .928 & $133,11 \%$ \\
\hline Mei & $\mathrm{Rp}$ & 526.240 .740 & $\mathrm{Rp}$ & 505.347 .661 & $104,13 \%$ \\
\hline Juni & $\mathrm{Rp}$ & 1.026 .010 .631 & $\mathrm{Rp}$ & 902.035 .327 & $113,74 \%$ \\
\hline Juli & $\mathrm{Rp}$ & 701.751 .697 & $\mathrm{Rp}$ & 606.420 .163 & $115,72 \%$ \\
\hline Agustus & $\mathrm{Rp}$ & 602.451 .281 & $\mathrm{Rp}$ & 563.230 .110 & $106,96 \%$ \\
\hline September & $\mathrm{Rp}$ & 1.122 .217 .302 & $\mathrm{Rp}$ & 1.061 .236 .196 & $105,75 \%$ \\
\hline Oktober & $\mathrm{Rp}$ & 828.628 .333 & $\mathrm{Rp}$ & 622.530 .037 & $133,11 \%$ \\
\hline November & $\mathrm{Rp}$ & 909.776 .421 & $\mathrm{Rp}$ & 814.884 .000 & $111,64 \%$ \\
\hline Desember & $\mathrm{Rp}$ & 1.018 .036 .959 & $\mathrm{Rp}$ & 954.496 .149 & $106,66 \%$ \\
\hline Total & $\mathrm{Rp}$. & $\mathbf{1 1 . 7 6 9 . 7 8 4 . 9 4 7}$ & $\mathrm{Rp}$ & $\mathbf{1 0 . 0 9 4 . 3 5 7 . 5 6 8}$ & $\mathbf{1 1 6 , 6 0 \%}$ \\
\hline
\end{tabular}

Perhitungan indeks produktivitas dari PT ABC Malang, berfluktuatif dengan rata-rata produktivitas $116 \%$, dibawah harapan manajemen yang mengharapkan indeks produktivitas rata-rata per tahun $125 \%$

\subsection{Menghitung Indeks Kinerja Lingkungan dari PT ABC Malang}

Indeks kinerja lingkungan yang dapat diperoleh dengan menganalisa limbah padat dan cair yang dihasilkan PT ABC Malang dibandingkan dengan standar baku mutu yang ditetapkan, selanjutnya kandungan limbah diranking berdasarkan tingkat bahaya dan dilakukan pembobotan dengan mempergunakan AHP, sehingga diperoleh hasil sebagai berikut : 
Tabel 3.2 Hasil Perhitungan Indeks EPI

\begin{tabular}{|c|c|c|c|c|c|c|c|}
\hline $\begin{array}{l}\text { Jenis } \\
\text { Limbah }\end{array}$ & Parameter & $\begin{array}{l}\text { Baku } \\
\text { Mutu }\end{array}$ & Rangking & $\begin{array}{c}\text { Hasil } \\
\text { Analisis } \\
(\mathrm{mg} / \mathrm{L})\end{array}$ & $\begin{array}{l}\text { Bobot } \\
\text { (Wi) }\end{array}$ & $\begin{array}{c}\text { Penyimpangan } \\
\text { (Pi) }\end{array}$ & $\begin{array}{c}\text { Indeks EPI } \\
(\text { Wi x Pi) }\end{array}$ \\
\hline \multirow{7}{*}{ Cair } & TSS & 100 & 11 & 48,7 & 0,018 & $51,30 \%$ & 0,009 \\
\hline & $\mathrm{Cr}$ (Krom Total) & 0,5 & 5 & 0,0174 & 0,090 & $96,52 \%$ & 0,087 \\
\hline & Minyak \& Lemak & 5 & 10 & 1,28 & 0,022 & $74,40 \%$ & 0,016 \\
\hline & NH3-N (Amonia Total) & 10 & 9 & 0,2184 & 0,029 & $97,82 \%$ & 0,028 \\
\hline & Sulfida $(\mathrm{H} 2 \mathrm{~S})$ & 0,8 & 8 & 0,2814 & 0,039 & $64,82 \%$ & 0,025 \\
\hline & BOD & 100 & 12 & 12,89 & 0,013 & $87,11 \%$ & 0,011 \\
\hline & $\mathrm{COD}$ & 250 & 13 & 30,2 & 0,011 & $87,92 \%$ & 0,010 \\
\hline \multirow{6}{*}{ Padat } & Mercury $(\mathrm{Hg})$ & 0,2 & 1 & 0,0014 & 0,232 & $99,30 \%$ & 0,230 \\
\hline & Plumbun $(\mathrm{Pb})$ & 5 & 3 & 0,0405 & 0,162 & $99,19 \%$ & 0,161 \\
\hline & Cadmium $(\mathrm{Cd})$ & 1 & 2 & 0,0198 & 0,167 & $98,02 \%$ & 0,164 \\
\hline & Chrom $(\mathrm{Cr})$ & 5 & 4 & 0,0964 & 0,101 & $98,07 \%$ & 0,099 \\
\hline & Copper $(\mathrm{Cu})$ & 10 & 6 & 0,0378 & 0,064 & $99,62 \%$ & 0,064 \\
\hline & Zink $(\mathrm{Zn})$ & 50 & 7 & 0,1365 & 0,054 & $99,73 \%$ & 0,054 \\
\hline \multicolumn{7}{|c|}{ Total Nilai Indeks EPI } & 0,959 \\
\hline
\end{tabular}

Nilai Indeks EPI dari pengolahan limbah di PT ABC Malang sebesar 0,959. Nilai indeks tersebut mengambarkan bahwa perusahaan telah melakukan kinerja lingkungan dengan baik, dimana kandungan limbah cair dan padat sesuai dengan baku mutu yang ditetapkan. Namun bila dikaitkan dengan pencapaian produktivitas perusahaan yang belum sesuai harapan, masih perlu dilakukan kajian lebih lanjut untuk memecahkan permasalahan perusahaan.

\subsection{Mengidentifikasi permasalahan dengan diagram Ishikawa}

Tingginya volume sludge yang dikirim ke PPLI menjadi beban finansial yang cukup besar bagi perusahaan. Sehingga perlu diidentifikasi akar permasalahan agar menemukan solusi yang fokus dan terukur dengan memakai ishikawa diagram.

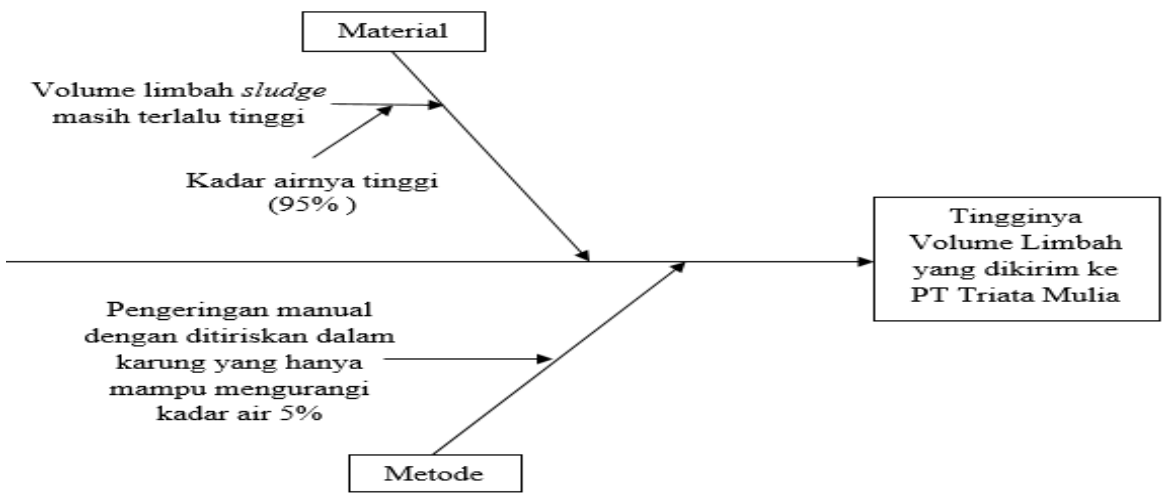

Gambar 3.1 Diagram Ishikawa

Dari diagram tersebut diketahui permasalahan utama PT ABC Malang adalah terkait banyaknya volume limbah yang dikirim ke PPLI disebabkan tingginya kadar air dalam sludge. Sehingga target yang diharapkan perusahaan mampu mereduksi kadar air sludge turun hingga $<95 \%$ atau kekeringannya meningkat $>50 \%$ Dry Solid.

\subsection{Sikronisasi Tujuan Perusahaan Dengan Target.}

Untuk mencapai tujuan PT ABC Malang yaitu mereduksi kadar air dalam sludge guna menekan beban finansial biaya pengolahan limbah dan peningkatan produktivitas. Maka harus dilakukan sikronisasi antara tujuan dan target, agar solusi yang dihasilkan tepat sasaran. Sinkronisasi tujuan dan target melalui proses 
brainstorming dengan pihak PT ABC Malang menghasilkan usulan pembelian mesin belt Filter press, sebuah mesin pemisah zat padat dan cair dengan prinsip filtrasi kontak flokulasi kimia dan ekstrusi mekanis. Berikut ini 2 alternatif usulan mesin belt Filter press sebagai solusi permasalahan di PT ABC Malang

Tabel 3.3 Spesifikasi Mesin Alternatif Solusi

\begin{tabular}{|c|c|c|c|}
\hline \multicolumn{2}{|c|}{ Model } & QTE3-1000 & ZDY 1.0 \\
\hline \multicolumn{2}{|l|}{ Belt Width (mm) } & 1000 & 1000 \\
\hline \multicolumn{2}{|l|}{ Dried sludge (kg/hr) } & 125 & 100 \\
\hline \multicolumn{2}{|c|}{ Mud Cake Content's Rate (\%) } & 75 & 60 \\
\hline \multicolumn{2}{|c|}{ Power Consumption (kW) } & 1,85 & 1,11 \\
\hline \multicolumn{2}{|c|}{ Lower Collecting Tray for Pressed Filtrate } & Yes & Yes \\
\hline \multirow{3}{*}{$\begin{array}{l}\text { External } \\
\text { Dimensions } \\
\text { (Reference) }(\mathrm{mm})\end{array}$} & $L$ & 2600 & 2600 \\
\hline & $W$ & 1800 & 1550 \\
\hline & $H$ & 2350 & 2540 \\
\hline \multicolumn{2}{|c|}{ Base Dimension L1 1 W1 (mm) } & $2100 \times 1330$ & $2100 \times 1300$ \\
\hline \multicolumn{2}{|c|}{ Reference Weight (kgs) } & 1210 & 1100 \\
\hline
\end{tabular}

Berdasar tabel diatas perbedaan dari ke 2 alternatif mesin yang diusulkan terletak pada kapasitas sludge per hari yang dapat diolah, konsumsi energi, kemampuan mereduksi prosentase kadar air dalam sludge. Sedangkan investasi yang diperlukan untuk pengadaan mesin 1 (QTE) dan mesin 2 (ZYD) masingmasing sebesar Rp. 557.056.500 dan Rp. 400.426.478.

\subsection{Pemilihan Alternatif Solusi Perbaikan}

Untuk memilih alternatif terbaik dilakukan analisa finansial, menggunakan annual worth yang didasarkan pada aliran kas (cash flow) yang terjadi dari masingmasing altenatif solusi. Sehingga diperoleh hasil seperti tabel berikut :

Tabel 3.4 Rekap Biaya dan Penghematan

\begin{tabular}{|c|c|c|}
\hline Jenis Biaya & Alternatif 1 & Alternatif 2 \\
\hline Biaya Investasi awal & Rp 557.056.500 & Rp. 400.462.487 \\
\hline Biaya bahan penunjang kimia & Rp 249.600.000 & Rp.249.600.000 \\
\hline Biaya Perawatan & Rp 32.000.000 & Rp. 29.000.000 \\
\hline Biaya Listrik & Rp 6.775.312 & Rp. 4.065.187 \\
\hline Total Biaya Operasional & Rp 287.528.398 & Rp.291.665.187 \\
\hline Penghematan & Rp 810.000.000 & Rp.648.000.000 \\
\hline
\end{tabular}

Setelah dilakukan perhitungan rekap biaya pengeluaran dan pemasukan, maka dilakukan perhitungan dengan metode annual worth menggunakan tingkat bunga $12,5 \%$ dan umur peralatan 5 tahun. Maka diperoleh hasil perhitungan sebagai berikut :

Annual Worth = A benefit $-\mathrm{A}$ cost

(Alternatif 1) $=$ Penghematan $-($ Biaya Investasi $(A / P, i \%, n)+$ Biaya Operasional $)$

$=R p$ 810.000.000 $-(\operatorname{Rp~557.056.500~(A/P,~12,5\% ,5)~+~Rp~288.375.312)~}$

$=\operatorname{Rp} 365.173 .120$

Annual Worth $=\mathrm{A}$ benefit $-\mathrm{A}$ cost

(Alternatif 2) $=$ Penghematan $-($ Biaya Investasi $(A / P, i \%, n)+$ Biaya Operasional $)$ $=R p 648.000 .000-(\operatorname{Rp~} 400.462 .487(A / P, 12,5 \%, 5)+R p 282.665 .187)$ $=\operatorname{Rp} 252.863 .306$ 
Bila Alternatif 1 dan 2 masing-masing diterapkan di PT ABC Malang. Maka akan terjadi perubahan terhadap total input terkait dengan penambahan konsumsi energi, biaya maintenance, biaya pengolahan limbah, sehingga akan berpengaruh terhadap indeks produktivitas berikut estimasi produktivitas bila masing-masing alternatif diterapkan :

Estimasi Produktivitas (Alternatif 1) $=($ Total Output $/$ Total Input $) \times 100 \%$

$$
\begin{aligned}
& =\frac{\operatorname{Rp} 11.769 .784 .947}{\operatorname{Rp~} 9.117 .383 .922} \times 100 \% \\
& =129 \%
\end{aligned}
$$

Estimasi Produktivitas (Alternatif 2$)=($ Total Output $/$ Total Input $) \times 100 \%$

$$
\begin{aligned}
& =\frac{\operatorname{Rp~} 11.769 .784 .947}{\operatorname{Rp~} 9.276 .673 .788} \times 100 \% \\
& =127 \%
\end{aligned}
$$

Implementasi dari alternatif 1 dan 2 tidak berpengaruh terhadap kandungan konsentrasi pada limbah, sehingga hasil perhitungan dari kedua alternatif diatas tidak mempengaruhi nilai EPI di PT ABC Malang, namun demikian nilai EPI dari PT ABC Malang menunjukkan bahwa kinerja lingkungangan perusahaan sudah baik.

\section{Kesimpulan}

Dari penelitian yang dilakukan diketahui bahwa permasalahan yang dihadapi PT ABC adalah tingginya volume sludge yang dikirim ke PPLI disebabkan kandungan air dalam sludge yang relatif tinggi sehingga target dari dari PT ABC Malang adalah mereduksi kandungan air dalam sludge hingga $>50 \%$ dry solid sehingga dapat menekan beban finansial dan meningkatkan produktivitas perusahaan.

Berdasarkan pengolahan data diperoleh nilai EPI (kinerja Lingkungan) dari PT ABC Malang sebesar 0.959 dimana kondisi ini menunjukkan performansi dan efisiensi perusahaan terhadap lingkungan dalam kondisi baik. Sedangkan solusi terpilih untuk perbaikan produktivitas adalah Alternatif 1 dengan penghematan biaya tahunan $\mathrm{Rp}$ 365.173 .120 serta nilai total produktivitas sebesar $129 \%$

\section{Daftar Pustaka}

[1] Bekti Prihatiningsih et al(2019) Prediction Spatial Model of Domestic Liquid Waste Distribution in Sawojajar Village, Malang City of Indonesia. International Journal of Multicultural and Multireligious Understanding. Volume 6 Issue 5 pp : 186 - 194

[2] Sumanth, David J. (1995). Productivity Engineering and Management. Mc Graw Hill Book Company

[3] Asian Productivity Organization. (2003). A Measurement Guide to Green Productivity .Tokyo.

[4] Pujawan, I Nyoman, (2008), Ekonomi Teknik, Penerbit Gunadarma, Surabaya.

[5] Radiana, F. (2005), Upaya Peningkatan Produktivitas dan Kinerja Lingkungan pada Proses Retanning dengan Metode Green Productivity, Tugas Akhir Teknik Industri ITS, Surabaya.

[6] Moses L. Singgih. (2008). Peningkatan Produktivitas Melalui Usaha Waste Reduction dengan Pendekatan Green Productivity pada PT ECCO TANNERY INDONESIA. Surabaya 